\title{
The Coevolution of Blue-Light Photoreception and Circadian Rhythms
}

\author{
Walter Gehring, ${ }^{1}$ Michael Rosbash ${ }^{2}$ \\ ${ }^{1}$ Biozentrum, University of Basel, Klingelbergstrasse 70, 4056 Basel, Switzerland \\ ${ }^{2}$ Howard Hughes Medical Institute, Brandeis University, Department of Biology, Waltham, MA 02454, USA
}

Received: 30 September 2002 / Accepted: 20 November 2002

\begin{abstract}
Sunlight is a primary source of energy for life. However, its UV component causes DNA damage. We suggest that the strong UV component of sunlight contributed to the selective pressure for the evolution of the specialized photoreceptor cryptochrome from photolyases involved in DNA repair and propose that early metazoans avoided irradiation by descending in the oceans during the daytime. We suggest further that it is not coincidental that bluelight photoreception evolved in an aquatic environment, since only blue light can penetrate to substantial depths in water. These photoreceptors were then also critical for sensing the decreased luminescence that signals the coming of night and the time to return to the surface. The oceans and the 24-h lightdark cycle therefore provided an optimal setting for an early evolutionary relationship between blue-light photoreception and circadian rhythmicity.
\end{abstract}

Key words: Cryptochromes - Circadian rhythms — UV avoidance — Photolyases

\section{Introduction}

Sunlight is essential for vision. Visual information is either directly transferred to effector organs, for example, flagella, and muscles, or processed in the brain to generate a percept of the three-dimensional world. Light also provides animals with information about time of day. The light-time signals are used to entrain the not exactly $24-\mathrm{h}$ endogenous circadian rhythms to the precise 24-h cycle of the earth's rotation. The circadian system therefore provides a representation of the fourth external dimension, time.

Visual photoreception in animals is based on opsin, with retinal as the chromophore. Some mammalian circadian photoreceptors are also rhodopsin-based, including the specialized melanopsin-containing retinal ganglion cells that connect to the suprachiasmatic nucleus (SCN) (Berson et al. 2002; Gooley et al. 2001; Hannibal et al. 2002; Hattar et al. 2002; Provencio et al. 2000, 2002). Although rhodopsins also contribute to Drosophila circadian photoreception (HelfrichForster et al. 2001), a major circadian photoreceptor in this organism was shown to be a cryptochrome, with flavin adenin dinucleotide (FAD) and methenyltetrahydrofolate (MTHF) as chromophores (Emery et al. 1998; Stanewsky et al. 1998). Mammalian cryptochromes may also be circadian photoreceptors (Selby et al. 2000; Thompson et al. 2001), although the evidence is stronger that they are important central clock components (Kume et al. 1999; van der Horst et al. 1999). Cryptochromes are closely related to photolyases (blue light-activated DNA repair enzymes), which led to the idea that the DNA binding property of photolyases was retained in cryptochromes (Cashmore et al. 1999; Emery et al. 1998). In this perspective, we suggest that the strong UV component of sunlight contributed to the selective pressure for the evolution of this specialized photoreceptor and that early metazoans avoided irradiation by descending in the oceans during the daytime. We suggest further that it is not coincidental that blue-light photoreception evolved in an aquatic environment, since 
only blue light can penetrate to substantial depths in water. This provided an optimal setting for the elaboration of blue light-dependent photoreception and a very early relationship with circadian rhythmicity.

\section{Diel Vertical Migrations of Zooplankton}

There are several ways to avoid the detrimental effects of UV irradiation. Most of these arose during the early phases of evolution, which occurred in the oceans. One exploits enzyme systems to repair the UV-induced DNA damage. Another involves protective pigmentation (e.g., carotenoids). This is apparently avoided by contemporary zooplankton, as it would make these organisms more visible to predators. A third is to avoid being irradiated, by descending to greater depths of water during the daytime. This strategy, and the evolutionary origin of circadian photoreceptors and rhythms, may be reflected by the diel vertical migrations of zooplankton that occur both in the oceans and in freshwater lakes.

Accounts of vertical migrations of planktonic animals date back to the nineteenth century, but these massive movements are best illustrated by sonar studies initiated during World War II. They revealed a phenomenon called the deep scattering layer, which was recorded at varying depths between 0 and $500 \mathrm{~m}$. This sonic scattering layer was later shown to consist of zooplankton, mainly crustaceans (copepods) and, to a lesser extent, mollusks. This layer is located near the surface of the ocean at night, descends in the morning to reach its greatest depth at noon, and comes up again in the evening. Several hypotheses have been advanced to explain these movements, but it is now generally agreed that light initiates and controls diel vertical migrations (Nybakken 2001). The organisms respond negatively to light, especially UV irradiation. In a study carried out in the Atlantic, there was a strong correlation between the diel vertical migration of the animals in the sonic scattering layer and the photic environment (Boden and Kampa 1967). The sonic-scattering layer was located with a precision echo sounder, and the animals accumulated within the narrow limits of $3.5-7.5 \times 10^{-4} \mu \mathrm{W} / \mathrm{cm}^{2}$ of blue light $(474 \mathrm{~nm})$. Changes in the cloud cover were reflected by predictable changes in the depth of the organisms. The hypothesis that diel vertical migrations are linked to illumination is further supported by studies in the polar seas (Bogorov 1946): under conditions of continuous daylight in the Arctic summer, there is an almost constant vertical distribution of the zooplankton in the Barents Sea over the entire 24-h period. In the autumn when day and night alternate, vertical migrations resume. Later studies provided some evidence that the diel vertical migrations of zooplankton depend on its food supplies and may also result from a predator-avoidance reaction (Lampert 1993; Ohman 1990). However, we consider these to be secondary responses, which evolved subsequent to the light response.

Among the freshwater animals studied most extensively is the water flea Daphnia, whose vertical migrations were described by Cuvier in 1829. Recent laboratory studies by Storz and Paul (1998) demonstrate that Daphnia responds to visible light (420-600 $\mathrm{nm}$ ) with positive phototaxis, whereas ultraviolet light leads to negative phototaxis. Sensitivity was maximal at $340 \mathrm{~nm}$, which corresponds closely to the value expected from the UV photoreceptors of its compound eye (Smith and Macagno 1990). These results were confirmed under field conditions by Leech and Williamson (2001), who demonstrated a vertical migratory response to UV radiation under full-spectrum solar irradiation. The migration consisted essentially of an ultraviolet-avoidance reaction. Similar UV avoidance was detected in planktonic marine sea urchin larvae (Pennington and Emlet 1986). Since UV radiation can penetrate up to $25 \mathrm{~m}$ depth in clear marine waters (Fleischmann 1989), and increased mortality rates were documented in both marine and freshwater organisms after exposure (Huntsman 1924; Klugh 1930), UV radiation represents a major selective force. Both field studies and laboratory experiments have led to the general conclusion that the zooplankton migrates to a depth of optimal light intensity (Cushing 1951; Leech and Williamson 2001). C.S. Pittendrigh (1993) also proposed "escape from light" as a major evolutionary driving force for the development of circadian rhythms. In light of the recent findings described below, we propose that the original driving force behind the diel vertical migrations is UV radiation, which provides selective pressure for these cyclic movements. The diel vertical migrations may be interpreted as an avoidance reaction to UV irradiation, leading to the coevolution of photoreception and circadian rhythms.

\section{Photolyases and DNA Repair}

Geological studies provide evidence that the atmosphere in precambrian times contained little oxygen, there was no protective ozone layer, and primitive organisms were exposed to heavy doses of UV irradiation during the daytime (Schopf et al. 1983). UV irradiation causes DNA damage by inducing the formation of photoproducts, mostly cyclobutane pyrimidine dimers and (6-4) pyrimidine photoproducts between adjacent bases on the same DNA strand. Bacteria have evolved enzymes capable of repairing these photoproducts, so-called photolyases that are also found in higher organisms. Photolyases 
are flavoproteins mediating DNA repair in a lightdependent manner (Sancar 1994). They are activated by blue light and contain flavin-adenine dinucleotide (FAD) as the catalytic chromophore and a second chromophore involved in light harvesting. The second chromophore is either methenyltetrahydrofolate (MTHF) or a deazaflavin (7,8-didemethyl-8-hydroxy5-deazariboflavin; 8-HDF). The excitation energy of the light harvesting chromophore is transferred to the catalytic chromophore. Photolyases bind selectively to pyrimidine dimers in UV-damaged DNA and transfer an electron from the excited state of the flavin to the pyrimidine dimer, which then repairs the DNA damage by isomerizing to yield the two original pyrimidines. There are two classes of photolyases (types I and II) that repair cyclobutane pyrimidine dimers, and another class involved in the repair of $(6$ 4) photoproducts, first identified in Drosophila (Todo et al. 1996). The fact that photolyases are activated by blue light may not be coincidental, since only blue light reaches substantial depths in water.

\section{Cryptochromes and the Circadian Clock}

To the same family of proteins as the light-activated photolyases belong the cryptochromes, blue-light photoreceptor proteins present in both plants and animals. In several species, cryptochromes are involved in the resetting of the circadian clock. The phylogenetic analysis of the photolyase-cryptochrome family strongly suggests that cryptochrome blue-light photoreceptors have evolved from photolyases, lost enzymatic activity, and evolved a mechanism for signaling to the internal clock (Cashmore et al. 1999; Sancar 2000). Cryptochromes were first identified as blue-light receptors in plants due to the power of Arabidopsis genetics. These proteins show a strong sequence similarity to photolyases. They also use FAD and MTHF as chromophores but lack detectable photolyase activity. Both CRY1 and CRY2 proteins of Arabidopsis function as blue-light receptors in the entrainment of the circadian rhythm (Devlin and Kay 2000).

The first indication that cryptochrome receptors also existed in animals and humans was the finding of a human gene related to Drosophila (6-4) photolyase (Todo et al. 1996). Proof that cryptochrome proteins are involved in animal clocks came first from genetic studies in Drosophila (Emery et al. 1998; Stanewsky et al. 1998; Egan et al. 1999; Selby and Sancar 1999; Okano et al. 1999). A mutant $\left(c r y^{\beta}\right)$ was isolated from a transgenic line of flies carrying a luciferase reporter gene fused to the clock gene period (per). In wild-type flies, the expression of the luciferase reporter oscillates with the circadian rhythm, whereas the $c r y^{\beta}$ mutation lacks cyclic expression of the reporter as well as other clock RNAs. As RNA cycling was restored by temperature entrainment, this suggested that light input was affected by the mutation. Although recent data suggest that CRY might also be a part of the core oscillator in Drosophila (Krishnan et al. 2001), the evidence is strong that CRY is a major circadian photoreceptor involved in light entrainment in this organism (Emery et al. 2000). Given the similarity between photolyases and cryptochromes, we suggest that these circadian photoreceptors originally functioned in the photorepair of DNA damage. They then became involved in the avoidance reaction to UV irradiation and, especially, in sensing the decreased luminescence that signals the coming of night and the time to return to the surface. This is because only blue light penetrates to the depths of the deep scattering layer. Very recently, Lin et al. (2002) have identified a new Drosophila circadian clock component, casein kinase $2 \alpha$. This enzyme has been previously implicated in Neurospora and plant clocks as well as in the response to UV damage in organisms ranging from yeast to humans, which supports an important role of light in the origins of circadian rhythms. Because photolyases interact with DNA as well as sense light, it is reasonable to imagine that the behavioral response to the 24-h light-dark cycle also involved direct cryptochrome-mediated changes in gene expression (Cashmore et al. 1999; Emery et al. 1998). This was presumably followed by a more sophisticated temporal program, in which an organism acquired the ability to anticipate the light-dark cycle and undergo these behavioral changes even in the absence of changes in light intensity, i.e., a free-running circadian clock. We therefore suggest that sunlight provided the driving force for the coevolution of these blue-light photoreceptors and circadian clocks.

\section{References}

Berson DM, Dunn FA, Takao M (2002) Phototransduction by retinal ganglion cells that set the circadian clock. Science 295:1070-1073

Boden BP, Kampa EM (1967) The influence of natural light on the vertical migrations of an animal community in the sea. Symp Zool Soc Lond 19:15-26

Bogorov BG (1946) Peculiarities of diurnal vertical migrations of zooplankton in polar seas. J Mar Res 6:25-36

Cashmore AR, Jarillo JA, Wu YJ, Liu D (1999) Cryptochromes: blue light receptors for plants and animals. Science 284:760-765

Cushing DH (1951) The vertical migration of planktonic Crustacea. Biol Rev Cambr Philos Soc 26:158-192

Cuvier G (1829) Le règne animal. Déterville, Paris, Vol IV, pp 164 171

Devlin PF, Kay SA (2000) Cryptochromes are required for phytochrome signaling to the circadian clock but not for rhythmicity. Plant Cell 12:2499-2510

Egan ES, Franklin TM, Hilderbrand-Chae MJ, McNeil GP, Roberts MA, Schroeder AJ, Zhang X, Jackson FR (1999) An extraretinally expressed insect cryptochrome with similarity to 
the blue light photoreceptors of mammals and plants. J Neurosci 19:3665-3673

Emery P, So WV, Kaneko M, Hall JC, Rosbash M (1998) CRY, a Drosophila clock and light-regulated cryptochrome, is a major contributor to circadian rhythm resetting and photosensitivity. Cell 95:669-679

Emery P, Stanewsky R, Hall JC, Rosbash M (2000) A unique circadian-rhythm photoreceptor. Nature 404:456-457

Fleischmann EM (1989) The measurement and penetration of ultraviolet radiation into tropical marine water. Limnol Oceanogr 34:1623-1629

Gooley JJ, Lu J, Chou TC, Scammell TE, Saper CB (2001) Melanopsin in cells of origin of the retinohypothalamic tract. Nat Neurosci 4:1165

Hannibal J, Hindersson P, Knudsen SM, Georg B, Fahrenkrug J (2002) The photopigment melanopsin is exclusively present in pituitary adenylate cyclase-activating polypeptide-containing retinal ganglion cells of the retinohypothalamic tract. J Neurosci 22:RC191

Hattar S, Liao HW, Takao M, Berson DM, Yau KW (2002) Melanopsin-containing retinal ganglion cells: Architecture, projections, and intrinsic photosensitivity. Science 295:10651070

Helfrich-Forster C, Winter C, Hofbauer A, Hall JC, Stanewsky R (2001) The circadian clock of fruit flies is blind after elimination of all known photoreceptors. Neuron 30:249-261

Huntsman AG (1924) Limiting factors for marine animals. The lethal effect of sunlight. Contrib Can Biol 2:82-88

Klugh AB (1930) The effect of the ultraviolet component of the sun's radiation upon aquatic organisms. Can J Res 2:312-317

Krishnan B, Levine JD, Lynch MK, Dowse HB, Funes P, Hall JC, Hardin PE, Dryer SE (2001) A new role for cryptochrome in a Drosophila circadian oscillator. Nature 411:313-317

Kume K, Zylka MJ, Sriram S, Shearman LP, Weaver DR, Jin X, Maywood ES, Hastings MH, Reppert SM (1999) mCRY1 and mCRY2 are essential components of the negative limb of the circadian clock feedback loop. Cell 98:193-205

Lampert W (1993) Ultimate causes of diel vertical migration of zooplankton: New evidence for the predator-avoidance hypothesis. Arch Hydrobiol 39:79-88

Leech DM, Williamson CE (2001) In situ exposure to ultraviolet radiation alters depth distribution of Daphnia. Limnol Oceanogr 46:416-420

Lin JM, Kilman VL, Keegan K, Paddock B, Emery-Le M, Rosbash M, Allada R (2002) A role for casein kinase 2alpha in the Drosophila circadian clock. Nature 420:816-820

Nybakken JW (2001) Marine biology: An ecological approach, 5th ed. Benjamin Cummings, San Francisco

Ohman MD (1990) The demographic benefits of diel vertical migration by zooplankton. Ecol Monogr 60:257-281

Okano S, Kanno S, Takao M, Eker AP, Isono K, Tsukahara Y, Yasui A (1999) A putative blue-light receptor from Drosophila melanogaster. Photochem Photobiol 69:108-113
Pennington JT, Emlet RB (1986) Ontogenetic and diel vertical migration of a planktonic echinoid larva, Dendraster excentricus (Escholtz): Occurrence, causes and probable consequences. Exp Mar Biol Ecol 104:69-95

Pittendrigh CS (1993) Temporal organization: Reflections of a Darwinian clock-watcher. Annu Rev Physiol 55:17-54

Provencio I, Rodriguez IR, Jiang G, Hayes WP, Moreira EF, Rollag MD (2000) A novel human opsin in the inner retina. J Neurosci 20:600-605

Provencio I, Rollag MD, Castrucci AM (2002) Photoreceptive net in the mammalian retina. This mesh of cells may explain how some blind mice can still tell day from night. Nature 415:493

Sancar A (1994) Structure and function of DNA photolyase. Biochemistry 33:2-9

Sancar A (2000) Cryptochrome: the second photoactive pigment in the eye and its role in circadian photoreception. Annu Rev Biochem 69:31-67

Schopf JW, Hayes JM, Walter MR (1983) Earth's Earliest Biosphere: Evolution of the earth's earliest ecosystems: Recent progress and unsolved problems. Princeton University Press, Princeton, NJ, pp 361-384

Selby CP, Sancar A (1999) A third member of the photolyase/bluelight photoreceptor family in Drosophila: a putative circadian photoreceptor. Photochem Photobiol 69:105-107

Selby CP, Thompson C, Schmitz TM, Van Gelder RN, Sancar A (2000) Functional redundancy of cryptochromes and classical photoreceptors for nonvisual ocular photoreception in mice. Proc Natl Acad Sci USA 97:14697-14702

Smith KC, Macagno ER (1990) UV photoreceptors in the compound eye of Daphnia magna (Crustacea, Branchiopoda). A fourth spectral class in single ommatidia. J Comp Physiol A 166:597-606

Stanewsky R, Kaneko M, Emery P, Beretta B, Wager-Smith K, Kay SA, Rosbash M, Hall JC (1998) The cryb mutation identifies cryptochrome as a circadian photoreceptor in Drosophila. Cell 95:681-692

Storz UC, Paul RJ (1998) Phototaxis in water fleas (Daphnia magna) is differently influenced by visible and UV light. J Comp Physiol A 183:709-717

Thompson CL, Blaner WS, Van Gelder RN, Lai K, Quadro L, Colantuoni V, Gottesman ME, Sancar A (2001) Preservation of light signaling to the suprachiasmatic nucleus in vitamin Adeficient mice. Proc Natl Acad Sci USA 98:11708-11713

Todo T, Ryo H, Yamamoto K, Toh H, Inui T, Ayaki H, Nomura T, Ikenaga M (1996) Similarity among the Drosophila (6-4) photolyase, a human photolyase homolog, and the DNA photolyase-blue-light photoreceptor family. Science 272:109112

van der Horst GT, Muijtjens M, Kobayashi K, Takano R, Kanno S, Takao M, de Wit J, Verkerk A, Eker AP, van Leenen D, Buijs R, Bootsma D, Hoeijmakers JH, Yasui A (1999) Mammalian Cry1 and Cry2 are essential for maintenance of circadian rhythms. Nature 398:627-630 